\title{
The interpretation of glucose clamp studies of long-acting insulin analogues: from physiology to marketing and back
}

\author{
S. G. H. A. Swinnen • F. Holleman • J. H. DeVries
}

Received: 27 February 2008 / Accepted: 12 June 2008 / Published online: 1 August 2008

(C) The Author(s) 2008

\begin{abstract}
Glucose clamp studies assessing the time-action profile of long-acting insulin analogues have reported conflicting results. In an attempt to reconcile the data, we organised an expert meeting of four leading European clamp groups, during which consensus was reached on some but not all points discussed. In this paper, which reflects our personal views only, we aim to provide guidance for readers and reviewers on the interpretation of this type of clamp study and to clarify its inherent limitations.

Glucose clamp studies are either performed manually or using an automated procedure, but differences in clamp methodology hardly seem a satisfactory explanation for the conflicting results. (Un)conscious investigator-related bias, especially during manual studies, cannot be ruled out, despite attempts at blinding the study insulin during the clamp.

The duration of action of study insulins is influenced by many factors, such as glucose and insulin levels prior to injection, endogenous insulin secretion, insulin dose, definitions used for onset and end of action, and insulin sensitivity (which is influenced by the necessity of fasting during the clamp). These factors limit the translation of clamp study results into daily practice.

Because of the inherent limitations of the glucose clamp technique and the lack of reproducibility of the outcomes, its results should be regarded as no more than an indication of the clinical action profile of long-acting insulin preparations.
\end{abstract}

Electronic supplementary material The online version of this article (doi:10.1007/s00125-008-1098-5) contains supplementary material, which is available to authorised users.

S. G. H. A. Swinnen $(\bowtie) \cdot$ F. Holleman • J. H. DeVries Department of Internal Medicine, Academic Medical Centre, Meibergdreef 9, Room F4-257,

1105 AZ Amsterdam, the Netherlands

e-mail: s.g.swinnen@amc.uva.nl
Keywords Insulin time-action profiles · Isoglycaemic clamp studies · Long-acting insulin analogues $\cdot$ Pharmacodynamics
Abbreviations
EMEA European Medicines Agency
GIR glucose infusion rate
GIR $_{\max }$ maximal glucose infusion rate
PD pharmacodynamic
$t_{\mathrm{GIRmax}}$ time to maximal glucose infusion rate

\section{Background}

Long-acting insulin analogues were developed to ameliorate the distinct peak action, the limited duration of action and the variable absorption of NPH insulin. Although they have modest additional clinical benefits compared with NPH insulin [1,2], their use is widespread. This is probably a result of the marketing message that these analogues are the ideal basal insulin replacement given their 'peakless', nearly $24 \mathrm{~h}$ duration of action [1]. This message was supported by a number of isoglycaemic clamp studies examining the pharmacodynamic (PD) or time-action profiles of the two currently available longacting insulin analogues, insulin glargine and insulin detemir. However, as we will show, these glucose clamp data are often difficult to interpret, frequently conflicting and sometimes misrepresented.

\section{The isoglycaemic clamp technique}

The isoglycaemic clamp technique was originally developed to measure tissue sensitivity to insulin. By keeping the 
glucose concentration constant, the physiological glucoseinsulin feedback loop, whereby the glucose concentration directly influences the insulin concentration and vice versa, is disrupted. The amount of i.v. glucose required to maintain (or 'clamp') the glucose concentration at the euglycaemic target level is equal to the glucose uptake of all tissues [3] and is expressed as glucose infusion rate (GIR) over time. When aiming to determine the glucoselowering effect of an insulin preparation the recorded GIR after s.c. injection provides a quantitative measure of its metabolic activity (i.e. the sum of the decrease in hepatic glucose production and the increase in glucose uptake) over time (Fig. 1) [4].

With regard to the registration of new insulin preparations, the European Medicines Agency (EMEA) considers data on time-action profiles using the isoglycaemic clamp technique to be 'of primary importance to demonstrate therapeutic equivalence or differences' between products $[5]$.

\section{Conflicting clamp data}

Glucose clamp studies examining the long-acting insulin analogues reported conflicting results [6]. For example, insulin glargine's time-action profile has been characterised as being flat [7,8] and as waxing and waning with a maximum effect approximately $10 \mathrm{~h}$ after injection [9-11]. Also, in one head-to-head study in type 2 diabetic patients the two long-acting insulin analogues were found to be comparable [10], whereas another comparison in individuals with type 1 diabetes showed lower total activity and a shorter duration of action for insulin detemir [12]. Some have attributed these conflicting findings to differences in study design, such as the study insulin dose [12], or to inherent differences in the PD profiles in type 1 vs type 2 diabetic patients [10]. Others have simply labelled inconsistent results as 'outlier findings' [6]. In an attempt to reconcile the data, and hypothesising that differences in study design and definitions used for PD endpoints contributed to the discrepant outcomes, we organised an expert meeting.

\section{Clampers' expert meeting}

Four leading European clamp groups involved in studies of long-acting insulin analogues participated in the expert meeting. The aim of the meeting was to explore the influence of various methodological differences between dissenting groups by discussing the physiological basis of glucose clamp studies. Our hope was that by emphasising science in a discussion highly influenced by industry interests, consensus would be reached on how to perform and interpret isoglycaemic clamp studies of long-acting insulin preparations.

Prior to the meeting, discrepancies and similarities between studies were identified in the relevant publications and categorised into four topics of discussion: clamp methodology, study design, outcome measures and statistical methods (Electronic supplementary material [ESM] Table 1).

Given the above-mentioned controversies, consensus was reached on many points during the meeting, such as the relevant physiological principles, the preferred experimental conditions and the desired mode of reporting of glucose clamp studies. ESM Table 2 provides a summary of these points. Despite this accord across several aspects

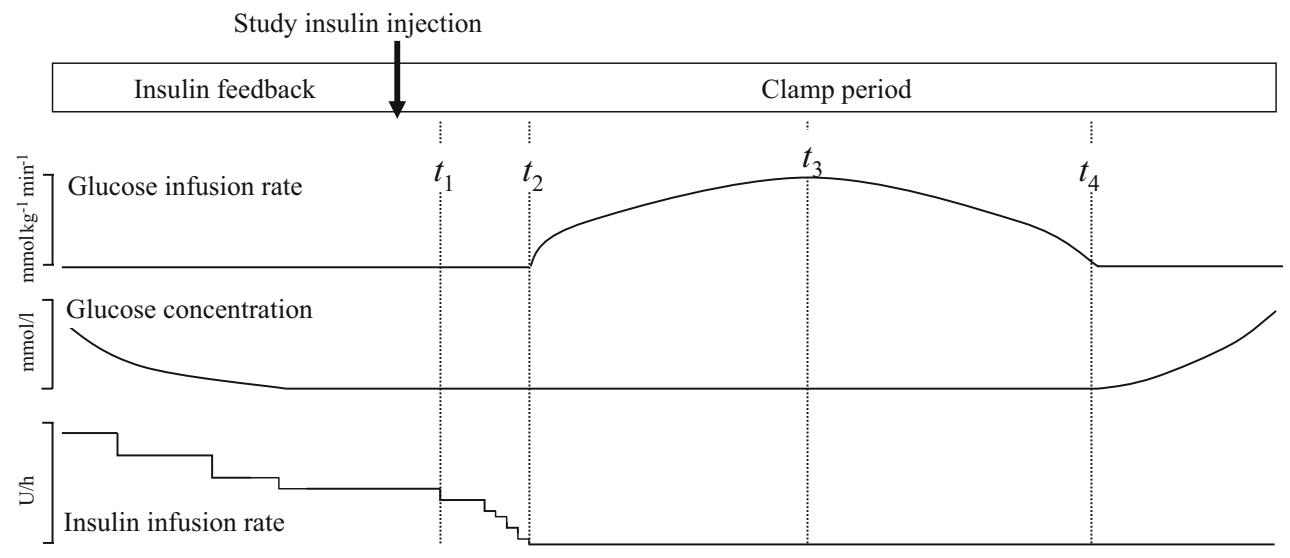

Fig. 1 Diagram of an isoglycaemic clamp in an individual with type 1 diabetes, i.e. without endogenous insulin secretion. During the 'insulin feedback' phase, prior to the administration of the study insulin, the glucose level is stabilised at the clamp glucose target level $(5.6 \mathrm{mmol} / \mathrm{l})$. As the action of the study insulin sets in ( $t_{1}$, onset of action), the i.v. insulin infusion is gradually decreased $\left(t_{1}\right.$ to $\left.t_{2}\right)$. Starting at this point, i.v. glucose is required to maintain the target level. Declining study insulin action is reflected by decreasing glucose requirement $\left(t_{3}\right.$ to $\left.t_{4}\right)$, ending in termination of the glucose infusion and subsequent rising of the glucose concentration above the clamp target ( $t_{4}$, end of action) 
of the clamp studies, there were also several points of disagreement. The present paper expresses our personal views only. Our aim is to provide guidance on the interpretation of papers reporting glucose clamp studies and to clarify the inherent limitations of the technique.

\section{Clamp methodology: Biostator vs manual clamp}

Glucose clamp studies can either be performed manually or by automated procedure using a Biostator (MTB Medizintechnik, Ulm, Germany). In most manual clamp studies of long-acting insulin analogues, arterialised plasma glucose has been measured at intervals of several minutes, with the investigator adapting the GIR, whereas the Biostator measures the arterialised blood glucose concentration every minute and adjusts the GIR according to a negative feedback algorithm based on the deviations of the glucose measurements from the clamp glucose target [13]. Study glucose targets and outcome measures of these methods are not interchangeable because blood glucose concentrations differ by approximately $11 \%$ from plasma values. However, this should not affect clamp study results, since the amount of glucose infused is not affected by slight differences in the clamp glucose target. When obtaining arterialised venous blood the sampling catheter is traditionally placed retrogradely in the vein, but evidence suggests that this is not strictly necessary [14].

The two techniques also differ in the way the glucose target is reached prior to the administration of the study insulin in studies of diabetic patients. During manual clamps, patients' glucose levels are lowered slowly by means of an i.v. infusion of human insulin to reach stable glucose concentrations. In Biostator studies of individuals with diabetes, insulin is infused at higher rates to quickly reduce glucose levels. The glucose infusion is subsequently started and both infusions are tapered to reach clamp target levels. As the onset of action of the study insulin is influenced by the insulin and glucose levels prior to its injection, this methodological difference may have contributed to the discrepant results reported for this PD outcome. However, it is unlikely to have had a major effect on the time-action profiles after some hours.

To allow proper comparison of the quality of different studies, it was agreed that this should be reported both as the mean and the SD of the glucose concentrations of the individual clamp procedures, and as the mean and SD of the SDs of the glucose concentrations of the individual clamp procedures. It was concluded that when clamps are of high quality (i.e. the mean glucose concentration during the clamp is close to the target level with few deviations), automated and manual clamp studies should not result in different time-action profiles, although definitive experi- mental evidence for this is lacking. However, during manual clamps, (un)conscious investigator-related bias cannot be ruled out, despite attempted blinding of the study insulin. This may explain why manual clamp studies have reported different time-action profiles for the same longacting insulin analogue $[12,15]$.

\section{Study design}

Whom to clamp: healthy volunteers vs type 1 or type 2 diabetic patients? The duration of action of insulins is most reliably measured in individuals with type 1 diabetes, as this excludes interference caused by endogenous insulin secretion. When not studying type 1 diabetic patients, endogenous insulin secretion should be suppressed, to ensure that the glucose requirement is exclusively dictated by the s.c. administered study insulin, i.e. not stimulated by erratic upward excursions of the glucose concentration. If it is not suppressed, endogenous insulin secretion can lead to augmented GIRs and thus overestimation of the duration of action. Stimulation of endogenous insulin secretion can be prevented by clamping at a sub-fasting glucose level, or by means of a continuous i.v. infusion of human insulin throughout the clamp (ESM Table 2). The disadvantage of the latter method is the metabolic effect of the infused insulin, which increases over time because of the increased insulin sensitivity resulting from the prolonged fast. This may again lead to overestimation of the duration of action of the study insulin (D. K. W. Soon, Exploratory and Program Medicine, Lilly-NUS Centre for Clinical Pharmacology, Singapore, personal communication). Moreover, suppression of endogenous insulin secretion is incomplete, with reported reductions in C-peptide levels to about $45 \%$ of the baseline values [16] or ' $>50 \%$ ' [8]. However, clamp studies in healthy volunteers may serve regulatory requirements (i.e. to support the registration of a new drug by a regulatory body such as the EMEA) and as a first indication of what to expect in diabetic patients.

The main argument in favour of performing clamp studies in type 2 diabetic patients is that they constitute the largest clinically relevant population. Although clamp studies of individuals with type 2 diabetes may overestimate duration of action as a result of the contribution of endogenous insulin, they reflect the durations that could be found in clinical practice.

When to clamp and how fasting limits the translation of clamp study results into daily practice Fasting improves apparent insulin sensitivity, thereby directly affecting the time-action profile of the insulin studied. As can be gathered from ESM Table 1, clamp duration, and therefore duration of fasting, ranged from 24 to $32 \mathrm{~h}$. Variation in the 
time of day the study insulin was administered also contributed to differences in the duration of fasting because the participants in the manual evening dosing studies received breakfast and lunch with short-acting insulin, while the individuals who took part in the automated clamp studies were administered study insulin late in the morning or at noon, resulting in an extended overnight fast $[10,16$, 17]. Such a prolonged fast leads to an increase in insulin sensitivity, which is also subject to diurnal changes (lowest in the early morning). Prolonged GIRs resulting from increased insulin sensitivity complicate the translation of the (duration of) action found in clamp studies into clinical practice.

To minimise differences in insulin sensitivity between and within study participants (when undergoing repeated clamps), the injection time, duration of fasting and any residual activity of pre-study insulin injections should be standardised, and changes in physical activity in the days preceding the study must be avoided. Carry-over effects from the participants' last pre-study basal insulin injection should be prevented by administration at least $36 \mathrm{~h}$ before clamp start, after which time glucose levels should be stabilised with a rapid-acting insulin s.c. or i.v. insulin infusion. The i.v. insulin should be started at least 4-6 h prior to study insulin administration. During this so-called 'insulin feedback', steady-state baseline glucose and insulin levels are attained. Ideally, the clamp glucose target should be reached at least $1 \mathrm{~h}$ before study insulin administration, without any glucose infusion during this last hour (Fig. 1). This can be very difficult to achieve and requires an operator with substantial experience.

Which insulin dose? The study insulin dose should constitute a clinically relevant dose, reflecting the mean requirement of the population under study. In studies investigating dose-response relationships, the various doses should also be within the normal requirement range. However, variations in study insulin dose do not account for the contradictory findings on the duration of action of the long-acting analogues, since doses were comparable $(0.35$ and $0.40 \mathrm{U} / \mathrm{kg}$ ). This is neatly illustrated in Fig. 1 of a recent review [6].

Considering the physiological function of basal insulin secretion (i.e. the suppression of hepatic glucose output), it should be noted that the ideally formulated long-acting insulin preparation, given at the optimum dose, in a study that maintains the ideal glucose target level $(5.6 \mathrm{mmol} / \mathrm{l})$, would result in no glucose infusion (GIR $=0 \mathrm{mmol} \mathrm{kg}{ }^{-1}$ $\mathrm{min}^{-1}$ ), without any escape of glucose concentration from the target level, by suppressing hepatic glucose sufficiently but without inducing a decrease in glucose level. Strictly speaking, when glucose has to be infused during a clamp, the study insulin has already been 'overdosed'. On the other hand, basal insulin needs when fasting during a clamp are different from day-to-day needs. Thus, again, although clamp studies may give us an impression of time-action profiles, translating the results into daily life is difficult.

Single vs repeated study injections The vast majority of studies have examined the time-action profile of a single s.c. injection, and only recently have two studies investigated PD profiles in a steady-state situation, i.e. after several days of s.c. administration of study insulin [12, 18]. Obviously, for long-acting insulin preparations with a duration of action over $24 \mathrm{~h}$, it is especially important to study steady-state time-action profiles as well. This should be done in diabetic patients and, again, the study insulin dose should be clinically appropriate for the study participants.

\section{Limitations of any definition of duration of action}

As discussed above, GIR may increase at the end of clamp procedures as a result of increasing insulin sensitivity associated with fasting, diurnal changes in insulin sensitivity and/or the contribution of endogenous insulin $[6,13]$. Other factors complicating the determination of the (absolute) duration of action of long-acting insulin preparations are their relatively low overall metabolic action at a given point in time and their very gradual onset and end of action. In addition, onset of action is difficult to determine because it is greatly influenced by the glucose and insulin levels prior to study insulin administration. Finally, it is not possible to define onset of action in steady-state conditions after repeated administration of long-acting insulin analogues. In single-injection studies, onset of action is best defined as the time after study insulin administration at which the i.v. insulin is gradually decreased ( $t_{1}$ of Fig. 1).

Declining study insulin action is reflected by a decreasing glucose requirement, ending in the termination of the i.v. glucose infusion and the subsequent spontaneous increase in the glucose concentration to above the clamp target. As the purpose of basal insulin preparations is to control fasting glucose at about $5.6 \mathrm{mmol} / \mathrm{l}(100 \mathrm{mg} / \mathrm{dl})$, the clinically appropriate definition of end of action is when no glucose infusion is required to prevent the glucose falling below that concentration (point $t_{4}$ of Fig. 1). However, the attendees at the expert meeting did not deem such a glucose level suitable to define end of action, as insulin action can seemingly disappear, only to reappear shortly thereafter. They defined end of action as the time after study insulin administration at which the glucose concentration increases to $>8.3 \mathrm{mmol} / \mathrm{l}(150 \mathrm{mg} / \mathrm{dl})$. However, the problem of disappearing and reappearing action potentially occurs at every chosen glucose cut-off value, and 
$8.3 \mathrm{mmol} / 1$ is clearly not a clinically appropriate glucose target level.

\section{Summarising individual data in one time-action profile}

In most reports of glucose clamp studies, individual timeaction profiles are averaged and depicted as a single mean curve. When applying this method it is essential that the GIRs for the study participants in whom end of action occurred before the end of study (by definition, GIR= $0 \mathrm{mmol} \mathrm{kg}{ }^{-1} \mathrm{~min}^{-1}$ ) are included in the calculation of the mean curve. Also, the number of participants that remain to constitute the mean curve, i.e. those in whom the end of action of the study insulin does not occur before the end of the clamp procedure, should be mentioned on the $x$-axis of the mean time-action profile. As information is lost by averaging individual curves, it was agreed that in addition to mean curves, individual PD profiles should be published, e.g. as an online appendix.

The GIR curves are usually smoothed, and the endpoints, maximal glucose infusion rate $\left(\mathrm{GIR}_{\max }\right)$ and time to $\operatorname{GIR}_{\max }\left(t_{\text {GIRmax }}\right)$, are derived from these smoothed profiles. These differ considerably from the unsmoothed GIR curve (Fig. 2), and the area under the GIR curve (GIR-AUC) should be calculated from raw data. Automated and manual clamp studies require different approaches to curve smoothing, as the glucose concentration is measured every minute by the Biostator vs every 3-5 min during manual clamps. As a result, GIR is less variable in manual clamping compared with automated studies, and therefore needs 'soft' smoothing. Data from Biostator-aided clamps require 'hard' smoothing by means of a regression technique. At present it is not clear whether different

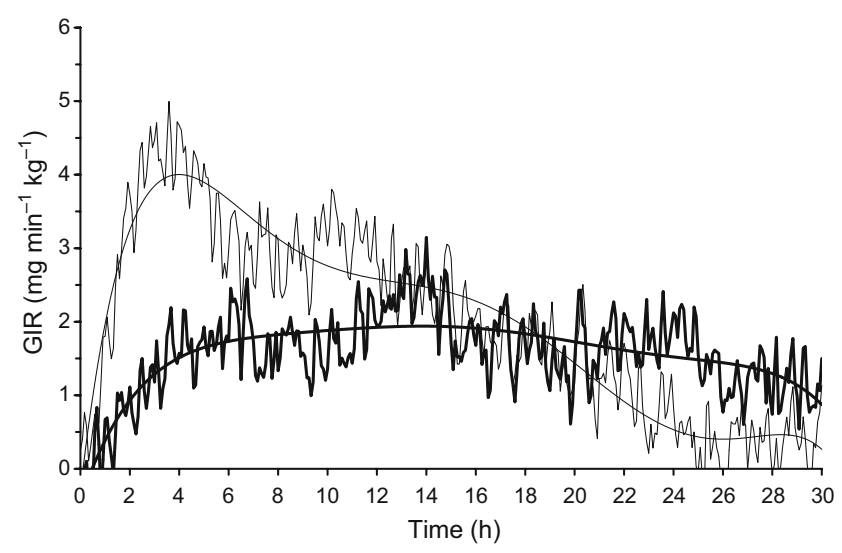

Fig. 2 Time-course of GIR in response to insulin glargine (black curve) and NPH insulin (grey curve) administration, showing both the raw data and the smoothed profiles. To convert GIR in $\mathrm{mg} \mathrm{kg}^{-1} \mathrm{~min}^{-1}$ into $\mathrm{mmol} \mathrm{kg} \mathrm{min}^{-1}$, multiply by 0.0055 . Reproduced with permission from Rave et al. [22] methods of smoothing create relevant differences in observed time-action profiles.

\section{Conclusions}

There was a high level of consensus among four leading European clamp groups about the relevant physiological principles, the preferred experimental conditions and the desired mode of reporting of glucose clamp studies. The described differences in clamp methodology hardly seem a satisfactory explanation for the conflicting results. The possibility that unintentional manipulation by the investigator during manual clamp studies may have contributed to discrepant outcomes cannot be ruled out. Whatever the reason for the contradictory results, the fact that the study results of one group cannot be confirmed by another limits the scientific validity of the clamp method for assessment of the time-action profile of long-acting insulins. Thus, the results of glucose clamp studies should be regarded as no more than an indication of the metabolic action of these insulin preparations.

Clinical trials are essential to determine the clinical action of insulin preparations. For example, when looking at the duration of action, a study showed that in $15-30 \%$ of patients with type 1 diabetes, the action of insulin glargine does not last up to $24 \mathrm{~h}$ and a second long-acting insulin injection is beneficial in these instances [19]. When looking at the peak effect, a clinical study demonstrated that insulin glargine is associated with a peak in hypoglycaemia rate at 6-12 h after administration, indicating at least some peak effect [20], which forcefully argues against a flat profile for insulin glargine. Similarly, injection of insulin detemir in the morning is associated with higher nocturnal and lower late-afternoon glucose levels, compared with detemir administration in the evening [21]. In conclusion, timeaction profiles of long-acting insulins determined by glucose clamp studies can be translated into clinical practice to only a limited extent, and clinical trials are essential to determine clinical action profiles.

\section{Epilogue}

On 19 April 2007, experts from four leading European clamp groups participated in a meeting chaired by the last author of this paper. The minutes of the meeting were approved by all participants after minor revisions. Subsequently, these minutes were rewritten into a scientific paper. All but one group commented and agreed to the paper. This group felt unable to co-author a paper 'with authors between whom disagreements largely exceed agreements'. Subsequently, a second group, which initially thought we 
'had covered the discussions very well', also withdrew as a co-author. Following this, we extensively rewrote the paper to produce the present article.

Acknowledgements The expert meeting was supported financially in equal amounts by Novo Nordisk and sanofi aventis. No company representatives were invited to, or attended the meeting, nor were they in any way involved in the writing of this manuscript.

Duality of interest S. G. H. A. Swinnen is employed by the Department of Internal Medicine of the Academic Medical Centre, partly through funding from both Novo Nordisk and sanofi aventis for the conduct of clinical trials. F. Holleman is currently principal investigator for a large multinational trial sponsored by sanofi aventis. J. H. DeVries and F. Holleman have received honoraria for consultancy work as well as research funding from Novo Nordisk and sanofi aventis.

Open Access This article is distributed under the terms of the Creative Commons Attribution Noncommercial License which permits any noncommercial use, distribution, and reproduction in any medium, provided the original author(s) and source are credited.

\section{References}

1. Holleman F, Gale E (2007) Nice insulins, pity about the evidence. Diabetologia 50:1783-1790

2. Horvath K, Jeitler K, Berghold A et al (2007) Long-acting insulin analogues versus NPH insulin (human isophane insulin) for type 2 diabetes mellitus. Cochrane Database Syst Rev 2:CD005613

3. DeFronzo RA, Tobin JD, Andres R (1979) Glucose clamp technique: a method for quantifying insulin secretion and resistance. Am J Physiol Endocrinol Metab 237:E214-E223

4. Heinemann L, Anderson JH (2004) Measurement of insulin absorption and insulin action. Diabetes Technol Ther 6:698-718

5. European Medicines Agency, Committee for Proprietary Medicinal Products (2002) Note for guidance on clinical investigation of medicinal products in the treatment of diabetes mellitus. Available from http://www.emea.europa.eu/pdfs/human/ewp/108000en.pdf, accessed 17 April 2008

6. Heise T, Pieber TR (2007) Towards peakless, reproducible and long-acting insulins. An assessment of the basal analogues based on isoglycaemic clamp studies. Diabetes Obes Metab 9:648-659

7. Lepore M, Pampanelli S, Fanelli C et al (2000) Pharmacokinetics and pharmacodynamics of subcutaneous injection of long-acting human insulin analog glargine, NPH insulin, and ultralente human insulin and continuous subcutaneous infusion of insulin lispro. Diabetes 49:2142-2148

8. Scholtz HE, Pretorius SG, Wessels DH, Becker RHA (2005) Pharmacokinetic and glucodynamic variability: assessment of insulin glargine, NPH insulin and insulin ultralente in healthy volunteers using a euglycaemic clamp technique. Diabetologia 48:1988-1995
9. DeVries JH (2006) To: Scholtz HE, Pretorius SG, Wessels DH, Becker RHA (2005) Pharmacokinetic and glucodynamic variability: assessment of insulin glargine, NPH insulin and insulin ultralente in healthy volunteers using a euglycaemic clamp technique. Diabetologia 48:1988-1995. Diabetologia 49:11251126

10. Klein O, Lynge J, Endahl L, Damholt B, Nosek L, Heise T (2007) Albumin-bound basal insulin analogues (insulin detemir and NN344): comparable time-action profiles but less variability than insulin glargine in type 2 diabetes. Diabetes Obes Metab 9:290 299

11. Luzio S, Dunseath G, Peter R, Pauvaday V, Owens D (2006) Comparison of the pharmacokinetics and pharmacodynamics of biphasic insulin aspart and insulin glargine in people with type 2 diabetes. Diabetologia 49:1163-1168

12. Porcellati F, Rossetti P, Busciantella NR et al (2007) Comparison of pharmacokinetics and dynamics of the long-acting insulin analogs glargine and detemir at steady state in type 1 diabetes: a double-blind, randomized, crossover study. Diabetes Care 30:2447-2452

13. Heinemann L (2004) Time-action profiles of insulin preparations. Kirchheim, Mainz

14. Goldfine AB, Ebbeling CB, Ludwig DS (2002) Antegrade intravenous catheterization for metabolic studies in man. Diabetologia 45:1742-1743

15. Plank J, Bodenlenz M, Sinner F et al (2005) A double-blind, randomized, dose-response study investigating the pharmacodynamic and pharmacokinetic properties of the long-acting insulin analog detemir. Diabetes Care 28:1107-1112

16. Heinemann L, Linkeschova R, Rave K, Hompesch B, Sedlak M, Heise T (2000) Time-action profile of the long-acting insulin analog insulin glargine (HOE901) in comparison with those of NPH insulin and placebo. Diabetes Care 23:644-649

17. Heise T, Nosek L, Ronn BB et al (2004) Lower within-subject variability of insulin detemir in comparison to NPH insulin and insulin glargine in people with type 1 diabetes. Diabetes 53:1614 1620

18. Porcellati F, Rossetti P, Ricci NB et al (2007) Pharmacokinetics and pharmacodynamics of the long-acting insulin analog glargine after 1 week of use compared with its first administration in subjects with type 1 diabetes. Diabetes Care 30:1261-1263

19. Ashwell SG, Gebbie J, Home PD (2006) Twice-daily compared with once-daily insulin glargine in people with type 1 diabetes using meal-time insulin aspart. Diabet Med 23:879-886

20. Ashwell SG, Gebbie J, Home PD (2006) Optimal timing of injection of once-daily insulin glargine in people with type 1 diabetes using insulin lispro at meal-times. Diabet Med 23:46-52

21. Philis-Tsimikas A, Charpentier G, Clauson P, Ravn GM, Roberts VL, Thorsteinsson B (2006) Comparison of once-daily insulin detemir with NPH insulin added to a regimen of oral antidiabetic drugs in poorly controlled type 2 diabetes. Clin Ther 28:15691581

22. Rave K, Nosek L, Heinemann L, Frick A, Becker R (2003) Timeaction profile of the long-acting insulin analogue insulin glargine in comparison to NPH insulin in Japanese volunteers. Diabetes Metab 29:430-431 